\title{
LICENCIATURAS NOS INSTITUTOS FEDERAIS: ASPECTOS PARA DISCUSSÃO
}

\author{
B. M. OLIVEIRA* e M. R. N. S. OLIVEIRA \\ Centro Federal de Educação Tecnológica de Minas Gerais \\ bruna_ifnmg@outlook.com*
}

Artigo submetido em outubro/2015 e aceito em dezembro/2015

DOI: $10.15628 /$ rbept.2016.3493

\section{RESUMO}

Este texto apresenta resultados parciais de estudo sobre os cursos de licenciatura em Institutos Federais de Educação, Ciência e Tecnologia. O estudo tem por objetivo compreender aspectos desses cursos quanto à condição de se eles contemplam ou não a docência para o ensino médio integrado, ou seja, na educação profissional integrada ao ensino médio. Além disso, aborda-se a natureza da oferta em questão, ou seja, se ela privilegia a docência das disciplinas acadêmicas ou das disciplinas técnicas. Os resultados parciais já obtidos, pela análise dos projetos político-pedagógicos de cursos dos Institutos Federais de Minas Gerais, sinalizam que, a despeito da oferta de ensino integrado nos Institutos e de alguns dos projetos mencionarem a intenção de formar professores para atuarem no integrado, os currículos analisados não contemplariam essa formação. Corrobora-se ainda o fato de que essas instituições continuam privilegiando as licenciaturas para as disciplinas científicas, apesar de serem instituições prioritariamente de educação profissional. Confirma-se, também, a continuidade da não exigência de requisitos legais de formação docente para atuação nas disciplinas técnicas da educação profissional de nível médio, mesmo considerando que essa modalidade de ensino situa-se no âmbito da educação básica.

PALAVRAS-CHAVE: formação docente; educação profissional; ensino médio integrado.

\section{UNDERGRADUATE IN BRAZILIAN FEDERAL INSTITUTES: ASPECTS FOR DISCUSSION}

\begin{abstract}
This paper presents partial results on teaching education programs offered by Brazilian Federal Institutes of Education, Science and Technology. The study aims to understand characteristics of those programs related to teaching at vocational education integrated to academic high school, which is named here as integrated education. Besides that, it approaches the nature of the offer in question, in other words, if it favors the teaching of academic disciplines or technical disciplines. Partial results already gotten by the analysis of politicalpedagogical projects programs of the Federal Institutes of Minas Gerais, indicate that, despite the integrated
\end{abstract}

education offering in institutes and some projects mention the intention to graduate teachers to work in integrated, curricula analyzed don't contemplate that graduation. It also corroborates the fact of those institutions continue favoring undergraduate for scientific subjects, despite of they are mainly institutions of vocational education. It is also confirmed continuity for not requiring of legal requirements for teaching education to work in the technical disciplines of high school vocational education, even considering that this type of education is located within the basic education.

KEYWORDS: teaching education; vocational education; integrated education 


\section{INTRODUÇÃO}

Ao se pensar na educação profissional técnica de nível médio (EPTNM) e em um projeto de educação que supere uma formação meramente técnica e a dualidade entre ensino geral e profissionalizante, entram em pauta os cursos técnicos integrados ao ensino médio e a formação do professor para atuar nesses cursos.

A possibilidade de integração entre o ensino técnico e o ensino médio foi retomada a partir

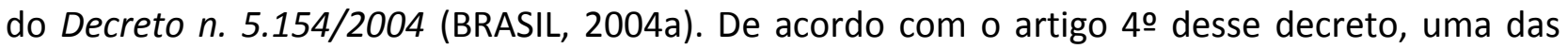
formas de articulação entre os cursos técnicos e o ensino médio é a integrada.

Segundo Frigotto, Ciavatta e Ramos (2012) a defesa de um projeto de ensino integrado, tal como regulamentado pelo decreto em pauta, foi construída levando-se em consideração a situação dos trabalhadores brasileiros, jovens e adultos, que necessitam de preparação profissional precoce, no próprio nível médio, para inserção no mundo do trabalho, a fim de garantir condições básicas de sobrevivência. $E$ isso na condição dominante e predominantemente capitalista da formação social brasileira, em que a divisão entre trabalho intelectual e manual implica uma diferenciação educacional: ensino propedêutico para uns e ensino técnico para outros.

Junto a isso, nos cursos técnicos integrados podem-se considerar dois grupos de docentes: os que ministram aulas nas disciplinas técnicas e os que se responsabilizam pelas disciplinas acadêmicas do ensino médio. De acordo com Pena (2014, p. 20-21), esse segundo grupo é formado por "professores licenciados, mas que não tiveram formação para trabalhar com a EPT", considerando as particularidades da mesma, tendo em vista os desafios da integração curricular com as disciplinas técnicas e a questão da formação profissional dos alunos".

Pensando justamente nas especificidades da modalidade da educação profissional (EP) e no professor que possui licenciatura voltada para a educação básica e que atua nessa modalidade, Moura (2008, p. 32) defende que:

é fundamental que o docente tenha uma formação específica que lhe aproxime da problemática das relações entre educação e trabalho e do vasto campo da educação profissional e, em particular, da área do curso no qual ele está lecionando ou vai lecionar no sentido de estabelecer as conexões entre essas disciplinas e a formação profissional específica, contribuindo para a diminuição da fragmentação do currículo.

A reflexão sobre o exposto e a necessidade de preparo de professores para atuarem no ensino integrado ganha destaque diante da expansão da Rede Federal de Educação Profissional, Científica e Tecnológica (RFEPCT), desde a segunda metade da década de 2000, e particularmente com a criação dos Institutos Federais de Educação, Ciência e Tecnologia (IFs), pela Lei n. 11.892/2008 (BRASIL, 2008a). Pelo artigo 8으 da lei, é obrigatório que eles ofertem $50 \%$ das vagas para a educação profissional técnica de nível médio, prioritariamente na forma de cursos integrados.

\footnotetext{
${ }^{1}$ EPT significa educação profissional e tecnológica.
} 
A expansão e a prescrição mencionadas implicam aumento do número de matrículas nos cursos técnicos no país. E por decorrência, há a necessidade de maior número de professores para essa modalidade de ensino. De acordo, com Oliveira e Burnier (2013, p. 161) “o plano de expansão da rede federal, para o período de 2005 a 2010, envolveu uma ampliação, nesse período, de quase 300.000 matrículas na EP e, junto a isso, mais de 11.000 novos cargos efetivos de professores". Em 2015, estima-se que esses números sejam maiores, o que traz à tona a questão da formação dos profissionais que estão ocupando e/ou irão ocupar esses novos cargos na rede federal.

A propósito dessa formação, há, ainda, que se concordar com Machado $(2008$, p.14) que afirma: "a carência de pessoal docente qualificado tem se constituído num dos pontos nevrálgicos mais importantes que estrangulam a expansão da educação profissional no país". Assim, conforme mencionado, a partir da nova perspectiva de integração e com a expressiva expansão quantitativa da oferta da EP, ressurge, de forma contundente, no cenário nacional, a discussão sobre a formação de professores para os cursos correspondentes, principalmente em relação à atuação no ensino integrado.

Além disso, é importante considerar que, a partir da sua criação, no final de 2008 , os IFs têm legalmente a obrigação de ofertar $20 \%$ das vagas para cursos de licenciatura e programas especiais de formação de professores para a educação básica e a educação profissional (BRASIL, 2008a). Nesse sentido, a rigor, fica evidente o papel dos IFs em atuarem na formação de professores em geral e na formação de professores para as disciplinas técnicas da EPTNM.

Por todo o exposto, o estudo, ao qual este texto se refere, teve como questão central: as propostas de formação dos cursos de licenciatura oferecidos nos Institutos Federais - instituições federais que ofertam educação profissional técnica de nível médio prioritariamente na forma integrada ao ensino médio - contemplam as singularidades e demandas próprias da proposta do ensino médio integrado?

$\mathrm{Na}$ condução da pesquisa, traçou-se o panorama numérico dos cursos de licenciatura ofertados na RFEPCT, no ano de 2014. Para tal, fez-se levantamento das licenciaturas oferecidas na rede, por meio de consulta aos seus sítios eletrônicos e ao sistema e-MEC. Juntou-se a isso a revisão da legislação pertinente, ou seja, a Lei de Diretrizes e Bases da Educação Nacional (LDB) no que se refere à formação de professores (BRASIL, 1996) e à EP (BRASIL, 2008b), a Resolução CNE/CP n. 01/2002 que institui Diretrizes Curriculares Nacionais para a Formação de Professores da Educação Básica (BRASIL, 2002) ${ }^{2}$ e a própria Lei n. 11.892/2008 que cria os Institutos (BRASIL, 2008a). Realizou-se, então a análise de projetos político-pedagógicos de cursos (PPCs) de licenciatura em ciências biológicas, oferecidos em Institutos Federais mineiros.

\section{O ENSINO MÉDIO INTEGRADO}

Conforme se sabe, pelo Decreto n. 5.154/2004 (BRASIL, 2004a) a EPTNM envolve as formas: integrada ou concomitante ao ensino médio e subseqüente.

\footnotetext{
2 Essa resolução foi revogada recentemente pela Resolução CNE/CP n. 2, de 1o de julho de 2015 (BRASIL, 2015). No entanto, a rigor, o conteúdo da nova resolução não parece interferir naquelas características das licenciaturas nos IFS tratadas no presente estudo, além do fato de que os cursos os de licenciatura existentes ainda não se adaptaram a ela.
} 
Na concepção da educação profissional técnica de nível médio, o termo integrado está presente na legislação como uma das formas pelas quais o ensino técnico e o médio acadêmico podem se articular. Entretanto, o que parece ocorrer na maioria dos cursos técnicos integrados é a realização de dois cursos, o médio e o técnico, com uma única matrícula em uma mesma instituição, tal como viabiliza o decreto em pauta, mas com currículos fragmentados, nos quais as disciplinas técnicas sequer dialogam com as acadêmicas.

Isso não condiz com o ensino integrado, tal como defendido pela concepção manifesta nas discussões do projeto de LDB e presentes no Seminário de Educação Profissional ocorrido no início do Governo Lula (BRASIL, 2004b), e que busca a superação da fragmentação curricular e a efetivação de um currículo que integre trabalho, ciência e cultura nos planos da formação geral e profissional (RAMOS, 2012). Esse projeto de ensino está associado à concepção de educação politécnica, com raízes na tradição socialista.

De acordo com Ciavatta (2014, p. 188) as expressões ensino integrado, politecnia e educação omnilateral não são sinônimas, mas tratam de "termos que pertencem ao mesmo universo de ações educativas quando se fala em ensino médio e educação profissional".

Conforme sinalizado, no cenário educacional brasileiro, a luta pelo ensino integrado remonta às lutas iniciadas na década de 1980 em defesa da escola pública e da educação dos trabalhadores, materializada principalmente em torno de um projeto de LDB que trazia em seu texto a proposta de uma formação politécnica. Esse projeto, no entanto, acaba sendo substituído pelo texto da LDB aprovada (BRASIL, 1996), consonante aos interesses dos organismos internacionais e à formação voltada para as necessidades do mercado de trabalho, tal como lembram Frigotto, Ciavatta e Ramos (2012). E o projeto não se compromete mais com a formação politécnica. No entanto, conforme os mesmos autores, é importante esclarecer que, dadas às condições reais de desigualdade presentes na sociedade brasileira, entende-se que o ensino médio integrado, tal como definido pelo Decreto $n$. 5.154/2004, ainda que não se constitua exatamente segundo o ideário de ensino politécnico, é um elemento necessário na travessia para a educação politécnica real (FRIGOTTO; CIAVATTA; RAMOS, 2012).

Sinteticamente, ensino médio integrado tem como característica básica e fundamental a relação entre o trabalho, a cultura e o conhecimento científico como eixos centrais de articulação do ensino médio com o ensino técnico, e que é concebido como etapa final da educação básica, com vistas à superação da histórica dualidade na educação e que expressa a dualidade estrutural da formação social brasileira.

Importa relembrar que o ensino integrado tem como pilar fundamental o ideário da escola unitária e da educação politécnica. Segundo Gramsci, a concepção de escola unitária do trabalho está relacionada ao ideal de uma "escola única inicial de cultura geral, humanista, formativa, que equilibre equanimente o desenvolvimento da capacidade de trabalhar manualmente [...] e o desenvolvimento de capacidades de trabalho intelectual" (GRAMSCI, 1991, p. 118 apud RAMOS, 2014, p. 210).

De forma particular, a concepção politécnica da educação relaciona-se à concepção de trabalho - o trabalho como princípio educativo geral - tomando-o no seu sentido ontológico, ou seja, compreendido como realização inerente ao ser, e no sentido histórico como prática econômica associada ao respectivo modo de produção. A politecnia contrapõe-se à concepção capitalista burguesa de fragmentação do trabalho e envolve a articulação entre trabalho 
intelectual e trabalho manual, implicando uma formação que, a partir do próprio trabalho social, desenvolva a compreensão das bases da organização do trabalho na nossa sociedade e que, portanto, permite que se compreenda o seu funcionamento (SAVIANI, 2003).

Com base no exposto, trabalho, ciência e cultura constituem as dimensões básicas de integração no ensino médio. Ramos (2008, p. 3) esclarece sobre o sentido que cada uma dessas dimensões assume dentro da perspectiva dessa integração:

O trabalho compreendido como realização humana inerente ao ser (sentido ontológico) e como prática econômica (sentido histórico associado ao respectivo modo de produção); a ciência compreendida como os conhecimentos produzidos pela humanidade que possibilita o contraditório avanço produtivo; e a cultura, que corresponde aos valores éticos e estéticos que orientam as normas de conduta de uma sociedade.

Dentro disso, o projeto de ensino médio integrado tem por objetivo a superação da dualidade entre formação profissional e formação geral e a divisão social do trabalho em trabalho manual e trabalho intelectual; tem como foco principal a pessoa humana e não o mercado de trabalho; implica uma formação mais completa e não orgânica à ideologia presente no capitalismo. Em outras palavras:

Trata-se de superar a redução da preparação para o trabalho ao seu aspecto operacional, simplificado, à parte dos conhecimentos que estão na gênese científico-tecnológica e na sua apropriação histórico-social. Como formação humana, o que se busca é garantir ao adolescente, ao jovem e ao adulto trabalhador o direito a uma formação completa para a leitura do mundo e para a atuação como cidadão pertencente a um país, integrado dignamente à sua sociedade política. Formação que, neste sentido, supõe a compreensão das relações sociais subjacentes a todos os fenômenos (CIAVATTA, 2012, p.85).

Assim, pode-se afirmar que a ideia de formação integrada, vai além de uma mera articulação ensino médio e ensino técnico; refere-se "a um tipo de formação que seja integrada, plena, vindo a possibilitar ao educando a compreensão das partes no seu todo ou da unidade do diverso" (CIAVATTA, 2014, p. 198).

\section{A DOCÊNCIA NO ENSINO MÉDIO INTEGRADO}

Para uma educação de qualidade social, ou seja, comprometida com a transformação societária e, assim, com a formação de sujeitos autônomos e críticos propositivos, o professor precisa ampliar a sua atuação para além do processo de ensino de apenas um dado conteúdo. Isso implica romper com o viés fragmentário da educação ainda presente na realidade escolar brasileira.

Isso posto, um primeiro aspecto, considerado de fundamental importância na formação de professores para o ensino médio integrado é o de que conceito a respeito seja um dos pilares dessa formação, envolvendo a formação de professores para as disciplinas técnicas da educação profissional técnica de nível médio e as disciplinas acadêmicas desse ensino. 
Outro aspecto primordial em um projeto dessa ordem diz respeito às atitudes dos sujeitos envolvidos com o ensino integrado. Araújo, Rodrigues e Silva (2014) explicitam sobre a necessária atitude humana transformadora, por parte desses sujeitos. E para os autores (2014, p. 169), a "atitude humana transformadora implica postura docente que transcenda ao simples exercício do cotidiano escolar". Isso significa romper com os padrões e determinações do modo de produção capitalista, tendo incorporadas, em si, ações que visem à construção e à efetivação de um projeto de formação integral do homem. Traduzindo isso em termos pedagógicos, "trata-se da postura docente que propicia um ensino em que pensar e fazer se encontram integrados no cotidiano escolar de qualquer disciplina" (ARAÚJO; RODRIGUES; SILVA, 2014, p. 170).

Importa também considerar que um dos requisitos necessários para o professor é conhecer a modalidade de ensino em que vai atuar. De acordo com Machado (2008, p. 18), o perfil do docente da EP engloba as especificidades das "dimensões próprias do planejamento, organização, gestão e avaliação desta modalidade educacional nas suas íntimas relações com as esferas da educação básica e superior".

Tendo em vista os mencionados aspectos que sustentam um projeto de ensino integrado e sua proposta de formação politécnica do sujeito, é necessário ao professor da EP "ser capaz de permitir que seus alunos compreendam, de forma reflexiva e crítica, os mundos do trabalho, dos objetos e dos sistemas tecnológicos dentro dos quais estes evoluem" (MACHADO, 2008, p. 18). Portanto, o professor precisa de outra atitude que deve ser traçada dentro de outro tipo formação, devendo ser crítica, reflexiva e orientada pela responsabilidade social (MOURA, 2008).

Assim, sobre o professor que atua no ensino integrado, Machado (2008, p. 17) considera:

deve saber integrar os conhecimentos científicos, tecnológicos, sociais e humanísticos, que compõem o núcleo comum de conhecimentos gerais e universais, e os conhecimentos e habilidades relativas às atividades técnicas de trabalho e de produção relativas ao curso técnico em questão.

Desta forma, não basta ao professor de biologia, matemática, física, português, etc., dominar os conhecimentos relativos a essas áreas do conhecimento. É preciso também conhecer um pouco sobre as áreas dos cursos técnicos em que atuam, a fim de superar a fragmentação do currículo e promover a integração em pauta. Para efetivar tal proposta, é necessário um trabalho em conjunto e que o docente da EP seja "um sujeito da reflexão e da pesquisa, aberto ao trabalho coletivo e à ação crítica e cooperativa, [...] que tem plena compreensão do mundo do trabalho e das redes de relações que envolvem as modalidades, níveis e instâncias educacionais" (MACHADO, 2008, p. 17).

Além disso, a atitude humana transformadora deve ser assumida por todos os sujeitos envolvidos a fim de se estabelecer "uma nova cultura institucional e social integradora" (ARAÚJO, RODRIGUES, SILVA, 2014, p. 170). Esses autores (2014, p. 172) ainda ressaltam a importância do "engajamento político-social com as mudanças estruturais e culturais da sociedade, na perspectiva de emancipação da classe trabalhadora", pois, nenhuma mudança curricular sozinha será capaz de efetivar transformação social.

Isso posto, a análise preliminar de seis projetos político-pedagógicos diferentes de cursos de Licenciatura em Ciências Biológicas oferecidos em três Institutos Federais mineiros - IF1, IF2 e 
IF3 - evidencia que, em apenas dois, menciona-se a intenção de formar o professor para o ensino médio integrado. Assim:

\begin{abstract}
O curso de Licenciatura em Ciências Biológicas, em seus diferentes momentos, irá propiciar aos alunos oportunidades de vivenciarem situações de aprendizagem de maneira a construir um perfil profissional adequado à formação de professores para a educação básica, e também compatível com a possibilidade de atuação na educação profissional, principalmente no caso do ensino médio integrado (IF1, grifos nossos).
\end{abstract}

Consoante a essa intenção, ainda que diferenciadas, as matrizes curriculares dos dois cursos mencionados, ambos de um mesmo instituto (IF1), trazem a disciplina denominada Educação profissional. Alguns dos tópicos abordados nessa disciplina são: histórico da educação profissional e técnica no Brasil; políticas educativas para os países em desenvolvimento; educação, trabalho e desenvolvimento; políticas públicas para a educação profissional no Brasil do neoliberalismo; e os dilemas da reforma da educação profissional. Além disso, em uma das bibliografias, aparece livro sobre ensino integrado. No entanto, as ementas dessa disciplina não trazem, de forma explícita, conteúdos ligados diretamente ao ensino integrado.

Importa registrar o fato de que no PPP do IF2 menciona-se que se pretende formar o professor para "desempenhar com competência as funções da docência em Ciências e Biologia na Educação Básica e Tecnológica". A menção à educação tecnológica revela a pretensão de formar um egresso que também atue na EP, mas não fica explícito se a pretensão está em formar o professor para atuar na educação profissional técnica de nível médio integrada ou não. Além disso, não existem na matriz curricular disciplinas que tratem particularmente da EP ou do próprio ensino integrado apesar de a disciplina Estrutura e funcionamento do ensino ter Ensino médio e técnico como um dos seus tópicos.

Os três PPPs do IF3, também diferentes entre si, não mencionam como parte do perfil profissional do egresso a atuação na EP, embora na matriz curricular de um dos cursos encontrarse referência a essa modalidade de ensino. Nessa direção, um dos tópicos da ementa da disciplina Políticas educacionais I é Educação profissionalizante e educação para o trabalho.

Constatou-se ainda que os componentes de formação específica e de formação pedagógica são oferecidos de forma pelo menos concomitante e que os projetos de curso foram construídos com base nas diretrizes específicas para a área da biologia e nas diretrizes para a formação de professores da educação básica.

Essa análise preliminar dos projetos político-pedagógicos demonstra que, em certa medida, existe preocupação dos IFs estudados em atender a demanda de formação de professores para a EP e o ensino médio integrado. Além disso, são projetos com características que não reforçam a minimização de cargas horárias em suas grades curriculares e expressam integração entre a formação específica e a formação pedagógica propriamente dita. No entanto, os currículos dessas licenciaturas não parecem dar ênfase à formação docente para a EP e para o ensino médio integrado. Destaca-se ainda que três dos PPPs analisados sequer mencionam a possibilidade de o egresso do curso atuar na EP. 


\section{A FORMAÇÃO DOCENTE NA LEGISLAÇÃO BRASILEIRA E A OFERTA DE LICENCIATURAS NOS INSTITUTOS FEDERAIS DE EDUCAÇÃO, CIÊNCIA E TECNOLOGIA}

O estudo realizado confima que não há, de fato, materialização nas escolas de exigência de requisitos de formação docente para atuação na EP. A LDB em sua versão original, a Lei n. 9.394/96 (BRASIL, 1996), estabelece diretrizes para a formação de docentes para atuarem na educação básica e na educação superior, mas não menciona diretamente a formação dos professores para a EP (OLIVEIRA; BURNIER, 2013).

No entanto, uma vez compreendido que a EPT é uma modalidade de ensino que envolve os níveis de educação básica e superior, entende-se que essa modalidade deve orientar-se pela legislação preconizada para esses dois níveis de ensino (PENA, 2014). Assim, tem-se nos artigos 62 e 66 da Lei n. 9.394/96 (BRASIL, 1996), respectivamente, que o professor da educação básica deve ter formação "em nível superior, em curso de licenciatura, de graduação plena" e que o docente da educação superior deve possuir formação "em nível de pós-graduação, prioritariamente em programas de mestrado e doutorado".

Além disso, a resolução das novas Diretrizes Curriculares Nacionais para a Formação de Professores da Educação Básica estabelece que as diretrizes referem-se à formação de professores que atuarão nas diferentes etapas e modalidades da educação básica, incluindo a educação profissional (BRASIL, 2015). No entanto, isso num contexto geral de definições precisas sobre a matéria, até o presente, o que, por hipótese, pode não implicar o rompimento com a tradição de não exigências na formação do professor da EP. Essa hipótese se justifica, pois a não exigência da licenciatura para a docência na EP continuou existindo, na prática, mesmo após a reformulação da LDB (BRASIL, 2008b), pela qual a EP é, então, afirmada como modalidade de educação.

Quanto à oferta da licenciatura nos IFs, diante da obrigatoriedade de essas instituições ofertarem cursos de formação docente, ocorre uma expansão desses cursos nas instituições da Rede Federal de Educação Profissional, Científica e Tecnológica. Por essa atribuição esperava-se que os IFs atuassem na formação de professores para as disciplinas técnicas da EP, atendendo às suas próprias demandas e contribuindo para a ruptura com a continuidade histórica da falta de formação de professores nesse campo. Porém um levantamento dos cursos de licenciatura que são oferecidos nessa rede, realizado em novembro de 2014, mostrou que as instituições privilegiam a oferta de licenciaturas para as disciplinas acadêmicas com poucos cursos voltados para a formação de professores das disciplinas técnicas.

Os cursos de licenciatura com oferta em maior quantidade de campi na rede federal são os de química ${ }^{3}$, matemática e física, estando os dois últimos empatados quanto ao número de ofertas; os de ciências biológicas vêm logo após, tal como evidencia a Tabela apresentada a seguir. A oferta predominante desses cursos, assim como a iniciativa de se ofertar licenciaturas nos IFs tem tido como uma das justificativas principais a falta de docentes nessas áreas ${ }^{4}$ (LIMA; SILVA, 2011). Importa registrar, no entanto, que a carência de profissionais docentes na educação básica está antes relacionada à pouca procura pelas licenciaturas e pelo magistério, junto aos altos índices de

\footnotetext{
${ }^{3}$ Química é considerada como uma área cientifica, mas também técnica.

${ }^{4}$ Sobre a defasagem de professores, cf. Ruiz, Ramos e Hingel (2007).
} 
evasão registrados nesses cursos, inclusive os ofertados pelos próprios IFs (OLIVEIRA, 2013) do que à baixa oferta dos mesmos.

Tabela: Licenciaturas na RFEPCT - 2014

\begin{tabular}{|c|c|}
\hline Cursos & $\begin{array}{l}\text { Quantidade de campi } \\
\text { que ofertam o curso }\end{array}$ \\
\hline Artes e Artes Visuais & 04 \\
\hline Biologia ou Ciências Biológicas & 29 \\
\hline Ciências Agrárias & 03 \\
\hline Ciências Agrícolas & 02 \\
\hline Ciências da Natureza & 03 \\
\hline Ciências da Natureza com habilitação em Biologia, Física ou Química & 02 \\
\hline Ciências da Natureza com habilitação em Química ou Química & 36 \\
\hline Ciências Sociais & 03 \\
\hline Dança & 02 \\
\hline Educação do Campo & 04 \\
\hline Educação Básica & 01 \\
\hline Educação Física & 06 \\
\hline Espanhol & 02 \\
\hline Física & 31 \\
\hline Geografia & 08 \\
\hline História & 01 \\
\hline Informática ou Computação & 18 \\
\hline Letras & 13 \\
\hline Matemática & 31 \\
\hline Mecânica & 01 \\
\hline Música & 03 \\
\hline Pedagogia & 07 \\
\hline Teatro & 01 \\
\hline TOTAL & 211 \\
\hline
\end{tabular}

Fonte: Sítios eletrônicos das instituições e sistema e-MEC. Acessos em novembro de 2014.

A propósito, ainda que a motivação da implantação de cursos de licenciatura nos IFs tenha implicado a necessidade de suprir as demandas da profissão docente, "as licenciaturas oferecidas pelos Institutos Federais revelam um lócus diferente daquelas oferecidas por outras instituições de educação superior" (LIMA, 2012, p.16). Os Institutos Federais são instituições especializadas na EPT e se apresentam com uma singularidade, que está pautada pela oferta da educação básica e superior, particularmente, na educação profissional média e superior, nas quais um mesmo docente pode lecionar.

Considerando que o espaço institucional e legal para a formação do professor da EP, como da educação básica em geral, no Brasil, é o curso de licenciatura, que se propõe a habilitar o futuro professor em termos de conhecimentos, habilidades e atitudes necessárias para o ensino, assumese que existe um conhecimento próprio à área do ensino que é básico para a formação do professor da EP. Entretanto, conforme afirmado, não se encontram, inclusive na própria rede federal, muitos cursos de licenciatura direcionados para a formação de professores para a EP e que contemplem, portanto, as especificidades que essa modalidade de ensino possui. 


\section{UMA ÚLTIMA PALAVRA}

Obviamente a formação docente é um dos pilares na construção do ensino integrado, pois, a efetivação de um currículo integrado só é possível se os docentes possuírem formação a respeito, embora se saiba que essa condição se relaciona também a questões de valorização da carreira e investimentos em melhoria das condições de trabalho do professor.

No entanto, por serem instituições especializadas na EPT e que ofertam o ensino técnico nas formas integrada ou não ao médio, os IFs podem se constituir em espaços profícuos para uma formação de professores que promova em seu currículo um diálogo promissor entre essas formas, estreitando-Ihes as relações. Urge lembrar que essas instituições têm a obrigatoriedade de oferta de $20 \%$ das suas vagas para os cursos e programas especiais de formação docente para a educação básica e profissional.

\section{REFERÊNCIAS}

1. ARAÚJO, R. M. L.; RODRIGUES, D. S.; SILVA, G. P. Ensino integrado como projeto político de transformação social. Trabalho \& Educação, Belo Horizonte, v.23, n.1, p.161-186, jan./abril 2014.

2. BRASIL. Lei n. 9.394/1996. Estabelece as Diretrizes e Bases da Educação Nacional. Brasília: MEC/SEF, 1996. Disponível em < http://portal.mec.gov.br/arquivos/pdf/ldb.pdf> Acesso em 20 out. 2014.

3.

Resolução CNE/CP n. 1/2002. Institui Diretrizes Curriculares Nacionais para a Formação de Professores da Educação Básica, em nível superior, curso de licenciatura, de graduação plena. Brasília: MEC, 2002. Disponível em <http://portal.mec.gov.br/cne/arqui vos/pdf/rcp01_02.pdf> Acesso em 26 dez. 2014

4. . Decreto n. 5.154/2004. Regulamenta o § 20 do art. 36 e os arts. 39 a 41 da Lei n. 9.394, de 20 de dezembro de 1996. Estabelece as diretrizes e bases da educação nacional, e dá outras providências. Brasília: MEC, 2004a. Disponível em <http://www.planalto.gov.br/ccivil_03/_ato2004-2006/2004/decreto/d5154.htm> Acesso em 12 dez. 2014.

5. BRASIL. MEC/SETEC. Proposta em discussão: políticas para a educação profissional e tecnológica. Brasília: MEC/SETEC, 2004b.

6. BRASIL. Lei n. 11.892/2008. Institui a Rede Federal de Educação Profissional, Científica e Tecnológica, cria os Institutos Federais de Educação, Ciência e Tecnologia, e dá outras providências. Brasília: MEC, 2008a. Disponível em: <http://www.planalto.gov.br/ccivil_03/_ato20072010/2008/lei//11892.htm> Acesso em 08 jan. 2013.

7 . Lei n. 11.741/2008. Altera dispositivos da Lei n. 9.394/1996, que estabelece as diretrizes e bases da educação nacional, para redimensionar, institucionalizar e integrar as ações da educação profissional. Brasília: MEC, 2008b. Disponível em: <http://www.planalto.gov.br/ccivil_03/_Ato2007-2010/2008/Lei/L11741.htm> Acesso em: 20 out. 2014.

8. BRASIL. CNE/CP. Resolução CNE/CP n. 2/2015. Define as Diretrizes Curriculares Nacionais para 
a formação inicial em nível superior (cursos de licenciatura, cursos de formação pedagógica para graduados e cursos de segunda licenciatura) e para a formação continuada. Brasília: MEC, 2015. Disponível em < http://portal.mec.gov.br/index.php?option=com_docman\&view= download\&alias=17719-res-cne-cp-002-03072015\&category_slug=julho-2015pdf\&ltemid=30192> Acesso em 22 jul. 2015.

9. CIAVATTA, M. A formação integrada: a escola e o trabalho como lugares de memória e identidade. In: FRIGOTTO, G; CIAVATTA; M.; RAMOS, M. (Orgs.) Ensino médio integrado: concepções e contradições. 3. ed. São Paulo: Cortez, 2012, p.83- 106.

10. . O Ensino integrado, a politecnia e a educação omnilateral. Por que lutamos? Revista Trabalho \& Educação, Belo Horizonte, v.23, n.1, p.187-205, jan./abril 2014.

11. FRIGOTTO, G; CIAVATTA, M; RAMOS, M. A gênese do Decreto n. 5.154/2004: um debate no contexto da democracia restrita. In: FRIGOTTO, G; CIAVATTA; M.; RAMOS, M. (Orgs.) Ensino médio integrado: concepções e contradições. 3. ed. São Paulo: Cortez, 2012, p.21-56.

12. LIMA, F. B. G. A formação de professores nos Institutos Federais de Educação, Ciência e Tecnologia: um estudo da concepção política. 2012. 282f. Dissertação (Mestrado em Educação) - Faculdade de Educação, Universidade de Brasília, Brasília-DF, 2012.

13. LIMA, F. B. G.; SILVA, K. A. C. P. C. As licenciaturas nos Institutos Federais: concepções e pressupostos. In: ENCONTRO ESTADUAL DE DIDÁTICA E PRÁTICA DE ENSINO, 4, 2011, Goiânia. Anais do IV Encontro Estadual de Didática e Prática de Ensino. Disponível em <http://www.ceped.ueg.br/anais/ivedipe/pdfs/didatica/co/40-164-2-SP.pdf> Acesso em 20 de junho de 2011.

14. MACHADO, L. R. S. Diferenciais inovadores na formação de professores para a educação profissional. Revista Brasileira da Educação Profissional e Tecnológica, Brasília, v.1, n.1, p.822, jun. 2008.

15. MOURA, D. H. A formação docente para a educação profissional tecnológica. Revista Brasileira da Educação Profissional e Tecnológica, Brasília, v.1, n.1, p.23-28, jun. 2008.

16. OLIVEIRA, B. M. Evasão nos cursos de licenciatura do Instituto Federal de Educação, Ciência e Tecnologia do Norte de Minas Gerais - Campus Salinas. 2013. 99f. Trabalho de Conclusão de Curso (Graduação em Licenciatura em Ciências Biológicas) - Instituto Federal do Norte de Minas Gerais, Salinas-MG, 2013.

17. OLIVEIRA, M. R. N.; BURNIER, S. Perfil das licenciaturas nos institutos federais de educação, ciência e tecnologia. In: CUNHA, D. M. et al. (Orgs.). Formação/profissionalização de professores e formação profissional e tecnológica: fundamentos e reflexões contemporâneas. Belo Horizonte: Editora PUC Minas, 2013, p.145-166.

18. PENA, G. A. C. Docência na educação profissional e tecnológica: conhecimentos, práticas e desafios de professores de cursos técnicos na rede federal. Tese (Doutorado em Educação) Faculdade de Educação, Universidade Federal de Minas Gerais, Belo Horizonte - MG, 2014.

19. RAMOS, M. Concepção de ensino médio integrado. 2008. Disponível em: <http://www.nre.seed.pr.gov.br/assischateaubriand/arquivos/File/curriculo_integrado.pdf> Acesso em 03 set. 2013.

20. . Possibilidades e desafios na organização do currículo integrado. In: FRIGOTTO, G; CIAVATTA; M.; RAMOS, M. (Orgs.). Ensino médio integrado: concepções e contradições. 3. 
ed. São Paulo: Cortez, 2012, p.107-128.

21. RAMOS, M. Filosofia da práxis e práticas pedagógicas de formação de trabalhadores. Revista Trabalho \& Educação, Belo Horizonte, v.23, n.1, p.207-218, jan./abril 2014.

22. SAVIANI, D. O choque teórico da politecnica. Trabalho, educação e saúde, Rio de Janeiro, v.1, n.1, p.131-152, 2003. 